\title{
Role of reactive oxygen species in the pathophysiology of human reproduction
}

\author{
Ashok Agarwal, Ph.D., HCLD, Ramadan A. Saleh, M.D., and \\ Mohamed A. Bedaiwy, M.D. \\ Center for Advanced Research in Human Reproduction, Infertility, and Sexual Function, Urological Institute \\ and Department of Obstetrics-Gynecology, Cleveland Clinic Foundation, Cleveland, Ohio
}

Objective: To summarize the role of reactive oxygen species (ROS) in the pathophysiology of human reproduction.

Design: Review of literature.

Setting: Fertility research center and obstetrics and gynecology department in a tertiary care facility.

Result(s): ROS plays an essential role in the pathogenesis of many reproductive processes. In male-factor infertility, oxidative stress attacks the fluidity of the sperm plasma membrane and the integrity of DNA in the sperm nucleus. Reactive oxygen species induced DNA damage may accelerate the process of germ cell apoptosis, leading to the decline in sperm counts associated with male infertility. ROS mediated female fertility disorders share many pathogenic similarities with the ones on the male side. These similarities include a potential role in the pathophysiology of endometriosis and unexplained infertility. High follicular fluid ROS levels are associated with negative IVF outcomes, particularly in smokers. Moreover, oxidative stress may be responsible in hydrosalpingeal fluid mediated embryotoxicity as well as poor in vitro embryonic development.

Conclusion(s): High levels of ROS are detrimental to the fertility potential both in natural and assisted conception states. (Fertil Steril ${ }^{\circledR} 2003 ; 79: 829-43$. (C2003 by American Society for Reproductive Medicine.)

Key Words: Female infertility, male infertility, oxidative stress, reactive oxygen species, spermatozoa

Cells living under aerobic conditions constantly face the oxygen $\left(\mathrm{O}_{2}\right)$ paradox: $\mathrm{O}_{2}$ is required to support life, but its metabolites such as reactive oxygen species (ROS) can modify cell functions, endanger cell survival, or both (1). Hence, ROS must be continuously inactivated to keep only a small amount necessary to maintain normal cell function. Oxidative stress (OS) arises as a consequence of excessive production of ROS and impaired antioxidant defense mechanisms (2). It is proposed that OS precipitates the range of pathologies that currently are thought to afflict the reproductive function (3). Recent reports have indicated that high levels of ROS are detected in semen samples of $25 \%$ to $40 \%$ of infertile men (4). The generation of ROS has become a real concern because of their potential toxic effects at high levels on sperm quality and function (5).

Spermatozoa are particularly susceptible to OS-induced damage because their plasma membranes contain large quantities of polyunsaturated fatty acids (PUFA) (6) and their cy- toplasm contains low concentrations of scavenging enzymes (1). Oxidative stress-mediated damage to the sperm plasma membrane may account for defective sperm function observed in a high proportion of infertility patients $(7,8)$. Oxidative stress attacks not only the fluidity of the sperm plasma membrane but also the integrity of DNA in the sperm nucleus (9). Oxidative stress-induced DNA damage may accelerate the process of germ cell apoptosis leading to the decline in sperm counts associated with male infertility and the apparent deterioration of semen quality observed over the past 4 to 5 decades.

In recent years, the role of ROS in female infertility has been investigated extensively. Peritoneal, follicular, and hydrosalpingeal fluids represent important reproductive microenvironments. Given the fact that these fluids harbor gametes, zygotes, and cleaving embryos for variable durations, any abnormality in their chemical composition may have deleterious effects on the reproductive processes. 
Although most of the mechanisms regulating ROS production and actions in both pathologic and physiologic cases remain to be elucidated, partial answers are now emerging. Elucidation of these mechanisms will enable researchers to create new, more effective methods to counteract the toxic effects of high levels of ROS and/or to improve fertility potential in assisted reproductive technologies. In this review, we summarize the efforts to explore the role of ROS in the pathophysiology of human reproduction.

\section{REACTIVE OXYGEN SPECIES AND SPERM PHYSIOLOGY}

Until recently, ROS were exclusively considered toxic to the human spermatozoa. However, a strong body of evidence suggests that small amounts of ROS are necessary for spermatozoa to acquire fertilizing capabilities $(9-12)$. The idea that limited amounts of ROS can intervene in a physiological manner in the regulation of some sperm functions was first evoked in a study by Aitken et al. (13). Those investigators found that low levels of ROS can enhance the ability of human spermatozoa to bind with zonae pellucida, an effect that was reversed by vitamin E. Other studies have found that incubating spermatozoa with low concentrations of hydrogen peroxide $\left(\mathrm{H}_{2} \mathrm{O}_{2}\right)$ stimulates sperm capacitation, hyperactivation, acrosome reaction, and oocyte fusion (14). Reactive oxygen species other than $\mathrm{H}_{2} \mathrm{O}_{2}$ such as nitric oxide and superoxide anion $\left(\mathrm{O}_{2}{ }^{-}\right)$have also been shown to promote sperm capacitation and acrosome reaction (15).

Reactive oxygen species must be continuously inactivated to keep only a small amount necessary to maintain normal cell function. Interestingly, seminal plasma is well endowed with an array of antioxidant defense mechanisms to protect spermatozoa against oxidants $(5,16-18)$. Antioxidants that are present in the seminal plasma compensate for the deficiency in cytoplasmic enzymes in the spermatozoa (19). Reactive oxygen species have a tendency toward chain reaction; that is, a compound carrying an unpaired electron will react with another compound to generate an unpaired electron, in such a manner that "radical begets radical." Hence, the basic problem is to break this chain reaction by the formation of nonradical end products (17).

Chain-breaking antioxidants such as $\alpha$-tocopherol (vitamin E) inhibit lipid peroxidation (LPO) in membranes by scavenging peroxyl $\left(\mathrm{RO}^{\circ}\right)$ and alkoxyl ( $\left.\mathrm{ROO}^{\circ}\right)$ radicals. The ability of $\alpha$-tocopherol to maintain a steady-state rate of peroxyl radical reduction in the plasma membrane depends on the recycling of $\alpha$-tocopherol by external reducing agents such as ascorbate or thiols (20). In this way, $\alpha$-tocopherol is able to function again as a free radical chain-breaking antioxidant, even though its concentration is low (21). For efficient interception, the radical to be intercepted must have a relatively long half-life (17). The peroxyl radicals are major reaction partners because their half-life extends into the range of seconds $(7 \mathrm{~s})$.
In contrast, the hydroxyl radical $\left(\mathrm{OH}^{*}\right)$, with its high reactivity and extremely short half-life $\left(10^{-9} \mathrm{~s}\right)$ cannot be intercepted with reasonable efficiency (22). Another line of antioxidant defense mechanisms is the prevention of excessive ROS formation. An example is the binding of metal ions, iron, and copper ions in particular, which prevents them from initiating a chain reaction (17).

\section{REACTIVE OXYGEN SPECIES AND MALE INFERTILITY}

It has been reported that levels of antioxidants in seminal plasma from infertile men are significantly lower than those in plasma from controls (23). However, pathological levels of ROS detected in semen from infertile men are more likely a result of increased ROS production rather than reduced antioxidant capacity of the seminal plasma (24). In some situations, the damage caused by oxidants may be repaired. Unfortunately, spermatozoa are unable to repair the damage induced by excessive ROS because they lack the cytoplasmic enzyme systems that are required to accomplish this repair. This is one of the features that makes spermatozoa unique in their susceptibility to oxidative insult (13).

Virtually every human ejaculate is contaminated with potential sources of ROS (25). It follows that some spermatozoa will incur oxidative damage and a concomitant loss of function in every ejaculate. Thus, the impact of ROS on male fertility is a question of degree rather than the presence or absence of the pathology. A study by Fisher and Aitken (26) has indicated that male germ cells at various stages of differentiation from pachytene spermatocytes to mature caudal epididymal spermatozoa from mature male rats, mice, hamsters, and guinea pigs have the potential to generate ROS. Clear evidence also suggests that human sperm can produce ROS $(27,28)$.

Spermatozoa may generate ROS in two ways: [1] the nicotinamide adenine dinucleotide phosphate (NADPH) oxidase system at the level of the sperm plasma membrane (29) and [2] the NADH-dependent oxido-reductase (diphorase) at the level of mitochondria (30). The mitochondrial system is the main source of ROS in spermatozoa from infertile men (31). Gomez et al. (32) have indicated that levels of ROS production by pure sperm populations were negatively correlated with the quality of sperm in the original semen. High levels of ROS production in human ejaculates may originate from morphologically abnormal spermatozoa and/or seminal leukocytes (33). The link between poor sperm quality and increased ROS generation lies in the presence of excess residual cytoplasm (cytoplasmic droplet).

When spermatogenesis is impaired, the cytoplasmic extrusion mechanisms are defective, and spermatozoa are released from the germinal epithelium carrying surplus residual cytoplasm. Under these circumstances, the spermatozoa that are released during spermiation are thought to be im- 
mature and functionally defective (34). Retention of residual cytoplasm by spermatozoa is positively correlated with ROS generation via mechanisms that may be mediated by the cytosolic enzyme glucose-6-phosphate dehydrogenase $\left(\mathrm{G}_{6} \mathrm{PD}\right)(9)$. Huszar and Vigue (35) have found that sperm morphological irregularities are significantly correlated with high creatine kinase (CK) activity in human spermatozoa. Similarly, recent studies have found an inverse relationship between CK levels and sperm morphological forms and have suggested that CK levels can be used as a reliable marker for sperm quality and fertilizing potential in subfertile men (36, 37). A positive relationship was found between CK activity and the rate of lipid peroxidation, as measured by malonaldehyde (MDA) formation, in sperm fractions separated by Percoll, as per Huszar and Vigue (38).

Recent studies by Ollero et al. (39) and Gil-Guzman et al. (28) have shown that levels of ROS production in semen were negatively correlated with the percentage of normal sperm forms as determined by the World Health Organization (40) classification and by the strict criteria of Kruger et al. (41). In the same studies, the authors found significant variation in levels of ROS production in subsets of spermatozoa at different stages of development. After Isolate gradient fractionation of ejaculated sperm, ROS production was found to be highest in the immature sperm fraction (containing sperm with abnormal head morphology and cytoplasmic retention) and lowest in the mature sperm fraction (containing normal-looking motile sperm) and in the immature germ cells.

The relative proportion of ROS-producing immature sperm was directly correlated with nuclear DNA damage values in mature sperm and inversely correlated with the recovery of motile, mature sperm. These interesting findings led to the hypothesis that oxidative damage of mature sperm by ROS-producing immature sperm during their comigration from seminiferous tubules to the epididymis may be an important cause of male infertility.

Studies from our institution also indicated that the production of ROS by human spermatozoa increased significantly when spermatozoa were exposed to repeat cycles of centrifugation $(42,43)$. The duration of centrifugation was found to be more important than the force of centrifugation for inducing ROS formation by human spermatozoa (44). These data are important because exposing spermatozoa to high levels of ROS may cause DNA fragmentation, which may have adverse consequences if they are used for assisted reproductive techniques (ARTs) (45). This may be true particularly in light of a recent report by Zini and co-workers (46), who found that the improvement in sperm motility after Percoll processing was not associated with a similar improvement in sperm DNA integrity. Those investigators recommended that the current sperm preparation techniques be reevaluated with the goal of minimizing sperm DNA damage.

\section{Role of Leukocytospermia in Excessive ROS Production in Semen}

Leukocytes are present throughout the male reproductive tract and are found in almost every human ejaculate (47). However, the clinical significance of increased leukocyte infiltration in semen, that is, leukocytospermia, is currently the subject of controversy (48). On one hand, leukocytospermia has been linked with poor sperm quality, reduced sperm hyperactivation, and defective sperm function (49). On the other hand, no correlation was found between seminal leukocyte concentrations and impaired sperm quality (50) or defective sperm function (51). The World Health Organization (WHO) defines leukocytospermia as the presence of peroxidase-positive leukocytes in concentrations of $>1 \times 10^{6}$ per milliliter of semen (40).

Peroxidase-positive leukocytes include polymorphonuclear leukocytes, which represent $50 \%$ to $60 \%$ of all seminal leukocytes, and macrophages, which represent another $20 \%$ to $30 \%$ (48). Peroxidase-positive leukocytes in semen are contributed largely by the prostate and the seminal vesicles (49). Peroxidase-positive leukocytes were found to be the major source of high ROS production in semen $(52,53)$. Activated leukocytes can produce 100-fold higher amounts of ROS than nonactivated leukocytes (31). Leukocytes may be activated in response to a variety of stimuli including inflammation and infection (54). Activated leukocytes increase nicotinamide-adenine dinucleotide phosphate (NADPH) production via the hexose monophosphate shunt.

The myeloperoxidase system of both polymorphonuclear leukocytes and macrophages is also activated, which leads to respiratory burst and production of high levels of ROS. Such an oxidative burst is an early and effective defense mechanism for killing microbes in cases of infection (55). Sperm damage from ROS that is produced by leukocytes occurs if seminal leukocyte concentrations are abnormally high, such as in leukocytospermia (53), or if seminal plasma was removed during sperm preparation for assisted reproduction (56).

However, Sharma et al. (57) observed that seminal leukocytes might cause OS even at concentrations below the WHO cutoff value for leukocytospermia. This may be due to the fact that seminal plasma contains large amounts of ROS scavengers but confers a very variable (10\% to $100 \%)$ protection against ROS generated by leukocytes (58). The lack of clinical significance of leukocytospermia reported in some studies is possibly a reflection of the powerful antioxidant properties of the seminal plasma, which may provide protection against leukocyte-mediated oxidative stress (OS) (50).

It is unclear from the existing literature whether the interaction between leukocytes and spermatozoa implies a direct or indirect stimulatory effect, which may enhance the capacity of spermatozoa to generate excessive ROS. Recent data from our center indicated that levels of ROS production 
Basal ROS levels in original cell suspensions (containing sperm and leukocytes) and in pure sperm suspensions (leukocyte-free sperm suspensions after complete removal of leukocytes using anti- $\mathrm{CD}_{45}$ coated paramagnetic beads) in three study groups.

\begin{tabular}{|c|c|c|c|c|c|c|}
\hline \multirow[b]{2}{*}{ Variable } & \multirow[b]{2}{*}{$\begin{array}{l}\text { Donors } \\
(\mathrm{n}=13)\end{array}$} & \multirow[b]{2}{*}{$\begin{array}{l}\text { Nonleukocytospermic } \\
\quad(\mathrm{n}=32)\end{array}$} & \multirow[b]{2}{*}{$\begin{array}{l}\text { Leukocytospermic } \\
\qquad(\mathrm{n}=16)\end{array}$} & \multicolumn{3}{|c|}{$P$ values } \\
\hline & & & & $\begin{array}{c}\text { Donors vs. } \\
\text { nonleukocytospermic }\end{array}$ & $\begin{array}{c}\text { Donors vs. } \\
\text { leukocytospermic }\end{array}$ & $\begin{array}{c}\text { Nonleukocytospermic vs } \\
\text { leukocytospermic }\end{array}$ \\
\hline $\begin{array}{l}\text { Basal ROS } \\
\qquad\left(\times 10^{6} \mathrm{cpm}\right)\end{array}$ & $0.4(0.1,2.5)$ & $2.7(0.53,12)$ & $178(32,430)$ & .06 & .0001 & $<.0001$ \\
\hline $\begin{array}{l}\text { Pure sperm ROS } \\
\quad\left(\times 10^{6} \mathrm{cpm}\right)\end{array}$ & $0.06(0.01,0.2)$ & $0.31(0.09,1.2)$ & $3.3(0.5,7.4)$ & .05 & .001 & .002 \\
\hline
\end{tabular}

Values are median (25th, 75th percentiles). ROS is measured by chemiluminescence assay.

Wilcoxon rank-sum test was used for comparison, and statistical significance was assessed at $P<.05$ level.

Agarwal. ROS and human reproduction. Fertil Steril 2003.

by pure sperm suspensions from infertile men with a laboratory diagnosis of leukocytospermia were significantly higher than were those from infertile men without leukocytospermia (Table 1) (59). In addition, seminal leukocyte concentrations were strongly correlated with levels of ROS in the original cell suspensions containing sperm and leukocytes (basal ROS); in the leukocyte-free sperm suspensions (pure sperm ROS); and in the leukocyte-free sperm suspensions (phorbol ester-induced ROS; Fig.1). This observation led to the postulation that seminal leukocytes play a role in enhancing sperm capacity for excessive ROS production either by direct sperm-leukocyte contact or by soluble products released by the leukocytes.

This new observation may have significant implications for the fertility potential of sperm both in vivo and in vitro. Excessive production of ROS by sperm in patients with leukocytospermia implies that both the free radical-generating sperm themselves and any normal sperm in the immediate vicinity will be susceptible to oxidative damage. Furthermore, once the process of LPO is initiated, its selfpropagating nature ensures a progressive spread of the damage throughout the sperm population.

\section{Pathological Effects of Increased ROS: the Concept of OS}

Generally, the term $O S$ is applied when oxidants outnumber antioxidants (17), when peroxidation products develop (60), and when these phenomena cause pathological effects (61). In the context of human reproduction, excessive ROS production that exceeds critical levels can overwhelm antioxidant defense strategies of spermatozoa and seminal plasma, causing OS $(2,62,63)$. All cellular components including lipids, proteins, nucleic acids, and sugars are potential targets for OS. The extent of OS-induced damage depends not only on the nature and the amount of ROS involved but also on the moment and duration of ROS exposure and on extracellular factors such as temperature, oxygen tension, and the composition of the surrounding environment (e.g., ions, proteins, and ROS scavengers).

\section{Lipid peroxidation of sperm plasma membrane}

Lipid peroxidation is broadly defined as "oxidative deterioration of PUFA," which are fatty acids that contain more than two carbon-carbon double bonds (64). The LPO cascade occurs in two fundamental stages: initiation and propagation. The hydroxyl radical $\left(\mathrm{OH}^{*}\right)$ is a powerful initiator of LPO (65). Most membrane PUFA have unconjugated double bonds that are separated by methylene groups. The presence of a double bond adjacent to a methylene group makes the methylene carbon-hydrogen bonds weaker, and therefore hydrogen is more susceptible to abstraction. Once this abstraction has occurred, the radical produced is stabilized by the rearrangement of the double bonds, which form a conjugated diene radical that can then be oxidized.

This means that lipids, which contain many methyleneinterrupted double bonds, are particularly susceptible to peroxidation. Conjugated dienes rapidly react with $\mathrm{O}_{2}$ to form a lipid peroxyl radical $\left(\mathrm{ROO}^{*}\right)$, which abstracts hydrogen atoms from other lipid molecules to form lipid hydroperoxides $(\mathrm{ROOH})$. Lipid hydroperoxides are stable under physiological conditions until they contact transition metals such as iron or copper salts. These metals or their complexes cause lipid hydroperoxides to generate alkoxyl and peroxyl radicals, which then continue the chain reaction within the membrane and propagate the damage throughout the cell (64). Propagation of LPO depends on the antioxidant strategies employed by spermatozoa. One of the by-products of lipid peroxide decomposition is MDA.

This by-product has been used in biochemical assays to monitor the degree of peroxidative damage sustained by spermatozoa (65). The results of such an assay exhibit an excellent correlation with the degree to which sperm function is impaired in terms of motility and the capacity for sperm-oocyte fusion (36). 


\section{FIGURE 1}

Correlation of seminal leukocyte concentrations with the following: levels of basal ROS (A); pure sperm ROS (B); and PMA-induced ROS in donors (•), non-leukocytospermic patients $(\boldsymbol{\nabla})$, and leukocytospermic patients $(\boldsymbol{\Delta} ; \mathbf{C})$. Basal ROS $=$ levels of ROS in washed sperm suspensions after simple wash and resuspension in phosphate-buffered saline (containing sperm and leukocytes); pure sperm ROS = levels of ROS in leukocyte-free sperm suspensions after complete removal of leukocytes using anti-CD $\mathrm{CD}_{45}$-coated paramagnetic beads. PMA-induced ROS = levels of ROS in leukocyte-free sperm suspensions after stimulation of phorbol 12-myristate 13-acetate. Seminal leukocyte concentrations $\left(\times 10^{6} / \mathrm{mL}\right)$ and levels of ROS $\left(\times 10^{6}\right.$ counted photons per minute per $20 \times 10^{6} \mathrm{sperm} / \mathrm{mL}$ ) were log transformed.
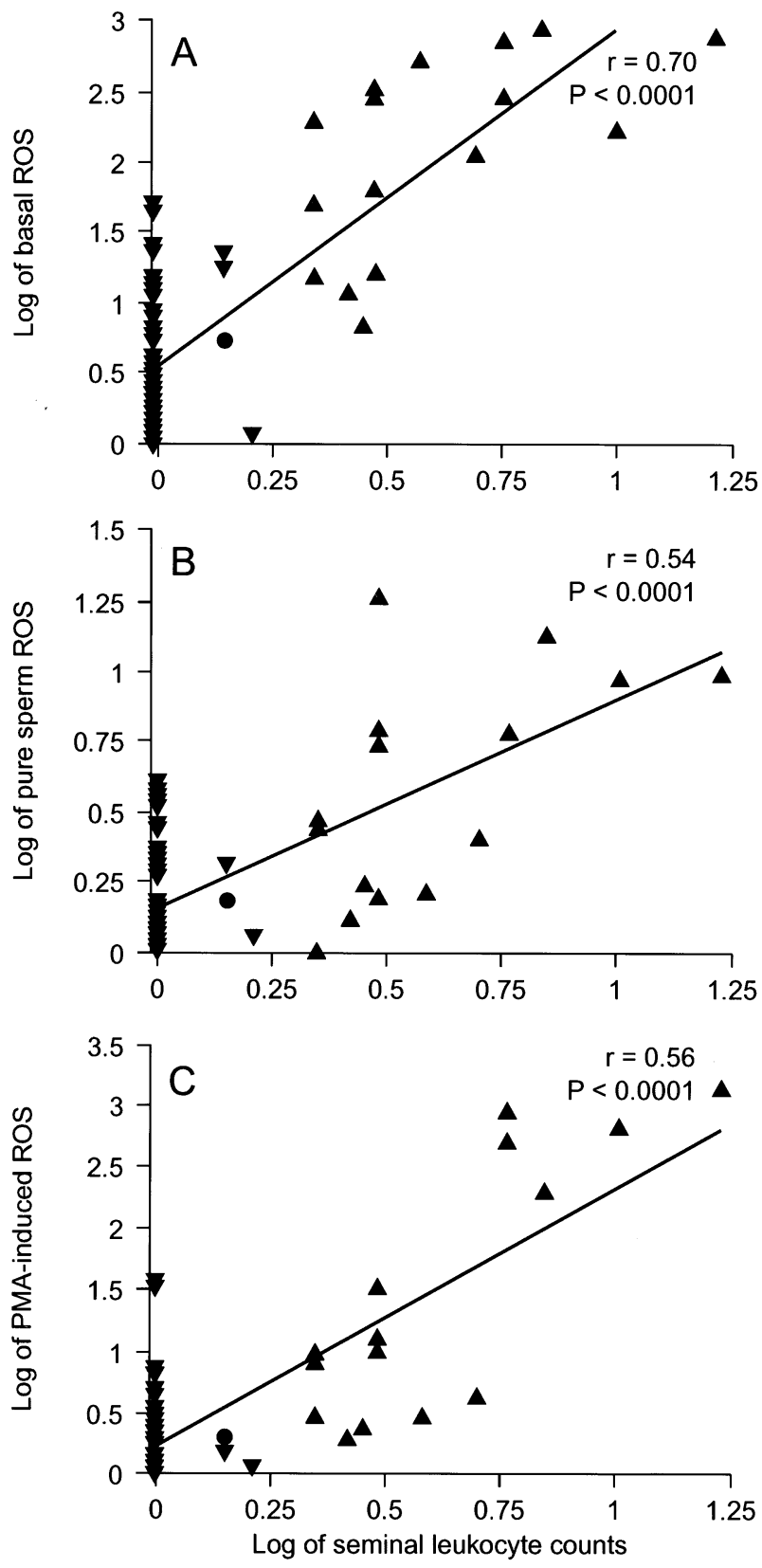

Agarwal. ROS and human reproduction. Fertil Steril 2003.

\section{Impairment of sperm motility}

The increased formation of ROS has been correlated with a reduction of sperm motility (66-68). The link between ROS and reduced motility may be due to a cascade of events that result in a decrease in axonemal protein phosphorylation and sperm immobilization, both of which are associated with a reduction in membrane fluidity that is necessary for spermoocyte fusion $(1,69)$. Another hypothesis is that $\mathrm{H}_{2} \mathrm{O}_{2}$ can diffuse across the membranes into the cells and inhibit the activity of some enzymes such as $\mathrm{G}_{6} \mathrm{PD}$. This enzyme controls the rate of glucose flux through the hexose monophosphate shunt, which in turn controls the intracellular availability of NADPH. This, in turn, is used as a source of electrons by spermatozoa to fuel the generation of ROS by an enzyme system known as NADPH oxidase (70).

Inhibition of $\mathrm{G}_{6} \mathrm{PD}$ leads to a decrease in the availability of NADPH and a concomitant accumulation of oxidized glutathione and reduced glutathione. This can reduce the antioxidant defenses of the spermatozoa and peroxidation of membrane phospholipids (71).

\section{Oxidative stress-induced DNA damage}

Two factors protect the sperm DNA from oxidative insult: the characteristic tight packaging of the DNA and the antioxidants present in the seminal plasma (72). Studies in which the sperm was exposed to artificially produced ROS resulted in a significant increase in DNA damage in the form of modification of all bases, production of base-free sites, deletions, frameshifts, DNA cross-links, and chromosomal rearrangements (73). Oxidative stress has also been correlated with high frequencies of single and double DNA strand breaks $(72,74)$. Strong evidence suggests that high levels of ROS mediate the DNA fragmentation commonly observed in spermatozoa of infertile men (75-78). This information has important clinical implications, particularly in the context of ARTs.

There is a substantial risk that spermatozoa carrying damaged DNA are being used clinically in this form of therapy (79). When IUI or IVF is used, such damage may not be a cause of concern because the collateral peroxidative damage to the sperm plasma membrane ensures that fertilization cannot occur with a DNA-damaged sperm. However, when intracytoplasmic sperm injection (ICSI) is used, this natural selection barrier is bypassed, and a spermatozoon with damaged DNA may be directly injected into the oocyte $(9,79)$.

\section{Oxidative stress and sperm suicide (apoptosis)}

Apoptosis, also described as programmed cell death, is a physiological phenomenon characterized by cellular morphological and biochemical alterations that cause a cell to commit suicide (80). Apoptosis is genetically determined and takes place at specific moments during normal embryonic life to allow definitive forms of tissues to develop. Apoptosis that occurs during adult life helps discard cells 
Comparison of apoptosis in spermatozoa from whole ejaculates and mature fraction in donors and infertility patients.

\begin{tabular}{lccc}
\hline Variable & $\begin{array}{c}\text { Donors } \\
(\mathrm{n}=17)\end{array}$ & $\begin{array}{c}\text { Infertility patients } \\
(\mathrm{n}=23)\end{array}$ & $P$ value $^{\mathrm{a}}$ \\
\hline Apoptosis in the whole ejaculate $(\%)$ & $6(4,8)$ & $12(9,16)$ & .001 \\
Apoptosis in the mature fraction (\%) & $12(7,14)$ & $20(11,27)$ & .04 \\
Apoptosis in the immature fraction (\%) & $7(5,11)$ & $9(6,13)$ & .25 \\
\hline
\end{tabular}

Values are median (25th, 75th percentiles).

${ }^{a}$ Wilcoxon rank-sum test was used for the analysis, and $P<.05$ was significant.

Agarwal. ROS and human reproduction. Fertil Steril 2003.

that have an altered function or no function at all (81). In the context of male reproductive function, apoptosis may be responsible for controlling the overproduction of male gametes $(82,83)$. The difficulty of designing in vitro models with which to dissect the molecular signaling pathways involved in the control of germ cell apoptosis has been the major cause of delay in understanding these pathways, compared with the case of other systems (84).

Apoptosis appears to be strictly regulated by extrinsic and intrinsic factors and can be triggered by a wide variety of stimuli. Examples of extrinsic stimuli that are potentially important in testicular apoptosis are irradiation (85), chemotherapy (86), and toxin exposure (87). Apoptosis-inducing genes such as p53, Bax, and Fas and apoptosis-suppressing genes such as Bcl-2 and c-kit play a prominent role in the genetic control of apoptosis (83). Animal studies have suggested that apoptosis is a key regulator of spermatogenesis in normal and pathological states. Spontaneous germ cell apoptosis has been identified in spermatogonia, spermatocytes, and spermatids in the testis of normal men and in patients with nonobstructive azoospermia $(88,89)$. Ejaculated spermatozoa have also been shown to demonstrate changes consistent with apoptosis.

The question to be answered is whether apoptosis in spermatozoa is the result of a process triggered at the spermatogonial level or if it occurs during the last phases of spermatogenesis or even at the post-testicular level. Gandini et al. (90) demonstrated that the percentage of apoptosis in the normozoospermic subjects was significantly lower than that in the men with oligoasthenoteratozoospermia, Hodgkin's disease, and testicular cancer. A recent study in our center used annexin- $\mathrm{V}$ staining assay to study the expression of phosphatidylserine, a marker of early apoptosis, in mature spermatozoa from infertility patients (unpublished data). Mature spermatozoa were separated by density gradient centrifugation. We found that the mature spermatozoa from infertility patients had significantly higher levels of apoptosis compared with the mature spermatozoa from a control group of normal sperm donors (Table 2).

In the same study, levels of apoptosis in mature spermatozoa were significantly correlated with levels of seminal
ROS, as determined by the chemiluminescence assay $(r=0.5, P=.006)$. Levels of caspase 3 and caspase 9 in ejaculated spermatozoa from infertility patients were significantly higher than that from the normal healthy sperm donors ( $P<.01$ and $P<.006$, respectively). In addition, levels of seminal ROS were positively correlated with levels of caspase $3(r=0.65, P<.01)$ and caspase $9(r=0.56, P<.001)$. The caspase gene family encodes a set of proteases responsible for carrying out programmed cell death. A ROS-dependent pathway for apoptosis was suggested based on the finding that $\mathrm{H}_{2} \mathrm{O}_{2}$ induces apoptosis in cell cultures (91).

High levels of ROS disrupt the inner and outer mitochondrial membranes. This results in the release of cytochrome-C protein from the mitochondria that activates the caspases and induces apoptosis (Fig. 2). On the other hand, Bcl-2, the inhibitor gene of programmed cell death, protects the cells from apoptosis, probably by mechanisms that reduce ROS production (92). Apoptosis in sperm may also be initiated by ROS-independent pathways involving the cell surface protein Fas (87). Fas is a type I membrane protein that belongs to the tumor necrosis factor-nerve growth factor receptor family and mediates apoptosis (93). When Fas ligand or agonistic anti-Fas antibody binds to Fas, apoptosis occurs (94).

In men with abnormal semen parameters, the percentage of Fas-positive spermatozoa can be as high as 50\%. Samples with low sperm concentrations are more likely to have a high proportion of Fas-positive spermatozoa (82). This evidence suggests that in subfertile men, the clearance of spermatozoa via apoptosis is not occurring correctly. The presence of spermatozoa that possess apoptotic markers such as positive Fas and DNA damage indicates that in men with abnormal semen parameters such as abnormal morphology, abnormal biochemical functions, and nuclear DNA damage, an "abortive apoptosis" has occurred $(34,82)$. Failure to clear Faspositive spermatozoa may be due to dysfunction at one or more levels. First, the production of spermatozoa may not be enough to trigger apoptosis in men with hypo-spermatogenesis.

In this case, Fas-positive spermatogonia may escape the signal to undergo apoptosis. Second, Fas-positive spermato- 


\section{FIGURE 2}

Events of apoptosis in human cells.

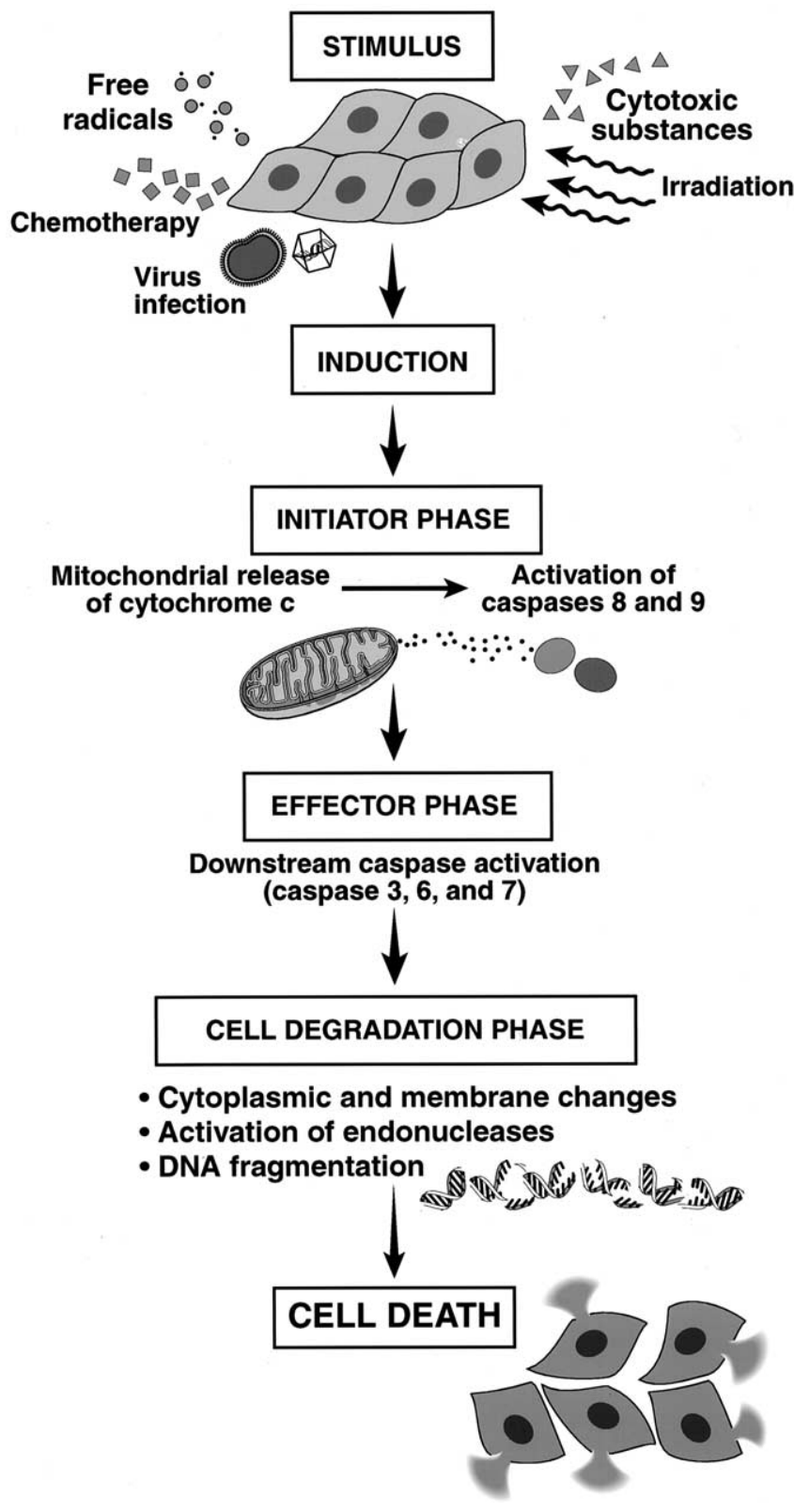

Agarwal. ROS and human reproduction. Fertil Steril 2003.

zoa may also exist because of problems in activating Fasmediated apoptosis. In the latter case, apoptosis is aborted and fails to clear spermatozoa that are earmarked for elimination by apoptosis (82). These findings implicate a prominent role for apoptosis in human male infertility and suggest that future research should look toward defining the mechanisms of regulation of apoptosis as a key mediator of abnormal human sperm production.

\section{Utility of seminal oxidative stress test in the infertility} clinic

Extensive research in the field of male infertility has been conducted to develop adequate indices of OS that would help determine, with accuracy, whether OS is a significant contributor in male infertility (95). Levels of OS vary greatly in infertile men (96). Because OS is an imbalance between levels of ROS production and antioxidant protection in semen, it is conceivable that assessment of OS will rely on the measurement of ROS as well as total antioxidant capacity (TAC) of semen. Levels of ROS can be measured in washed sperm suspensions (after simple wash and resuspension) using chemiluminescence assay (97). Total antioxidant capacity (TAC) in the seminal plasma can be measured using an enhanced chemiluminescence assay (98).

The fact that neither ROS alone nor TAC alone can adequately quantify seminal OS led to the logical conclusion that combining these two variables may be a better index for the diagnosis of the overall OS affecting spermatozoa (95). This conclusion led to the introduction of the ROS-TAC score as a new method for assessment of OS status in infertile men (95). The new ROS-TAC score is a statistical formula derived from levels of ROS in washed sperm suspensions and TAC in seminal plasma using principal component analysis. The resulting score minimizes the variability in the individual parameters of OS (ROS alone or TAC alone). The ROS-TAC score is an accurate measure of seminal OS, and low ROS-TAC scores indicate high seminal OS.

A cutoff value of 30 was determined as the lower limit of the normal range for the ROS-TAC score, and individuals with scores below this cutoff value were found to be at particular risk for prolonged inability to initiate pregnancies. Across all clinical diagnoses, the ROS-TAC score was a superior discriminator between fertile and infertile men than either ROS or TAC alone (Table 3) (95). The average ROS-TAC score for the fertile vasectomy-reversal men was nearly identical to that of normal fertile donors (98). Infertile men with an idiopathic or a male-factor diagnosis had significantly lower ROS-TAC scores compared with the case of the normal controls $(99,100)$. In addition, patients with a male-factor diagnosis who eventually initiated a successful pregnancy had significantly higher ROS-TAC scores than those who did not (100).

Our results also indicated that infertile men with a diagnosis of chronic prostatitis have significantly lower ROSTAC scores than controls (55). Infertile men with varicoceles were also found to have high levels of ROS, low levels of TAC (27), and low ROS-TAC scores (95). Varicocelectomy was associated with a significant increase in pregnancy and live birth rates for couples who underwent IUI, although standard semen parameters were not improved in all patients (101). This observation led to our speculation that the improvement in pregnancy rates after varicocelectomy may be 
Levels of ROS and TAC and ROS-TAC scores in subgroups of infertile men and controls.

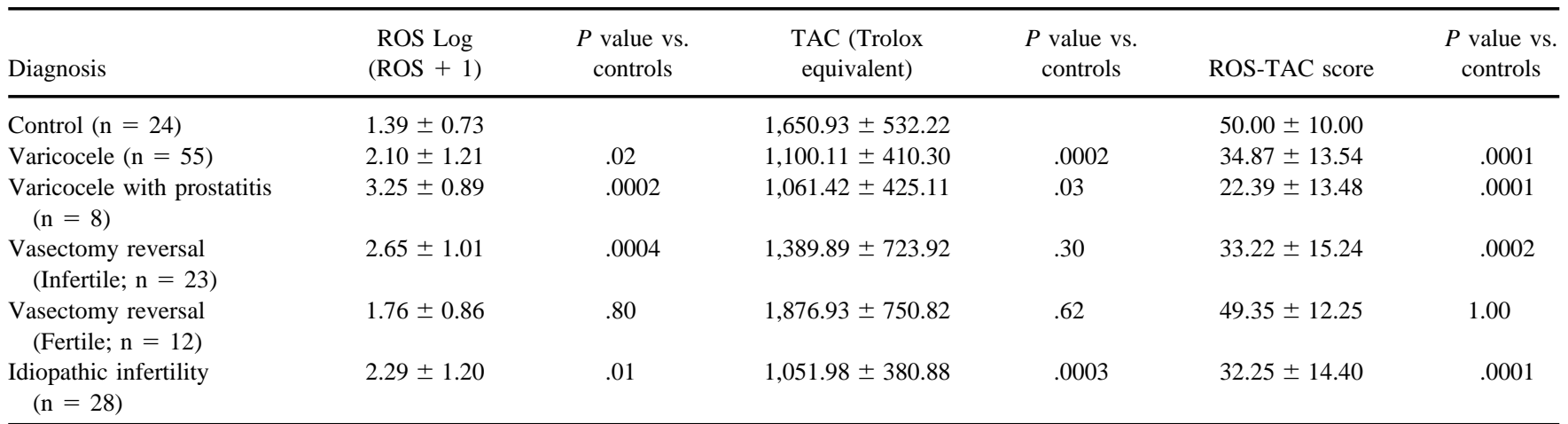

Non- $P$ values are mean \pm SD; pairwise $P$ values from Student's $t$ tests are adjusted using Dunnett's method. ROS $=$ reactive oxygen species in washed sperm suspensions (after simple wash and re-suspension in phosphate-buffered saline) measured by chemiluminescence assay; TAC $=$ total antioxidant capacity in seminal plasma measured by enhanced chemiluminescence assay; ROS-TAC score $=$ a statistical formula calculated using principal component analysis. Agarwal. ROS and human reproduction. Fertil Steril 2003.

due to a functional factor not tested during standard semen analysis, such as seminal OS. It is therefore possible that infertile men with varicocele may benefit from antioxidant supplementation (27). An earlier study on rats has indicated that free radical scavengers such as superoxide dismutase can prevent free radical-mediated testicular damage (102).

In a recent study (103), cigarette smoking in infertile men who had a normal genital examination was significantly correlated with increased levels of seminal OS, as evidenced by reduced ROS-TAC scores (Table 4). Reduced ROS-TAC scores in the infertile smokers may be due to the significant increase in seminal ROS levels and decrease in TAC levels. The finding of increased levels of seminal OS in association with cigarette smoking is of significance and may have important implications in the fertilizing potential of infertile men.

\section{REACTIVE OXYGEN SPECIES AND FEMALE INFERTILITY}

\section{Peritoneal Fluid ROS}

Peritoneal fluid containing immune-related cells is often seen in the vesicouterine cavity or the pouch of Douglas during gynecologic surgery. Peritoneal fluid bathes the pelvic cavity, uterus, fallopian tubes, and ovaries. It may be a major factor controlling the peritoneal microenvironment that influences the development and progression of endometriosis and endometriosis-associated infertility. Given the reproductive importance of the peritoneal fluid, it was the focus of a research study in which we attempted to define the relationship between its ROS levels and different infertility problems.

In a prospective study to determine whether ROS in peritoneal fluid is a factor in infertility, Wang et al. (104) compared levels of peritoneal fluid ROS in women with endometriosis and idiopathic infertility who underwent laparoscopy for infertility with levels in patients who underwent tubal ligation as controls. Those investigators found that ROS were present in the peritoneal fluid of patients with endometriosis and idiopathic infertility and in those who underwent tubal ligation.

Levels of ROS in patients with endometriosis and the control group in either unprocessed or processed (cell-free) peritoneal fluid were not statistically significantly different but did differ statistically significantly between patients with idiopathic infertility and controls in processed peritoneal fluid (Fig. 3). Macrophage concentrations of peritoneal fluid did not differ significantly between the controls and patients with endometriosis or idiopathic infertility.

Reactive oxygen species in the peritoneal fluid may not affect fertility directly in women with endometriosis. However, they may play a role in patients with idiopathic infertility. Levels of ROS in patients with endometriosis were not statistically significantly different from those of a control group (105). On the other hand, ROS levels were significantly higher in the idiopathic infertility patients than in the control group.

Reactive oxygen species levels were stable throughout the menstrual cycle in all groups. For the endometriosis group, ROS levels did not correlate with the stage of the disease (early vs. late). On the basis of the previous two studies, ROS may play a role in couples with unexplained infertility.

\section{Follicular Fluid ROS and the Outcome of IVF}

The follicular fluid environment surrounding the oocytes may play a crucial role in fertilization and embryo development. The oocyte resides in a metabolically active environment containing steroid hormones, growth factors, cyto- 
Comparison of oxidative stress indices (ROS, TAC, and ROS-TAC score) between donors, group 1 (smokers with a normal genital examination), and group 2 (nonsmokers with a normal genital examination).

\begin{tabular}{|c|c|c|c|c|c|c|}
\hline \multirow[b]{2}{*}{ Variable } & \multirow[b]{2}{*}{$\begin{array}{c}\text { Donors } \\
(\mathrm{n}=13)\end{array}$} & \multirow[b]{2}{*}{$\begin{array}{l}\text { Group 1 } \\
(\mathrm{n}=12)\end{array}$} & \multirow[b]{2}{*}{$\begin{array}{c}\text { Group 2 } \\
(\mathrm{n}=21)\end{array}$} & \multicolumn{3}{|c|}{$P$ values $^{\mathrm{a}}$} \\
\hline & & & & $\begin{array}{c}\text { Donors vs. } \\
\text { group } 1\end{array}$ & $\begin{array}{c}\text { Donors vs. } \\
\text { group } 2\end{array}$ & $\begin{array}{c}\text { Group } 1 \text { vs. } \\
\text { group } 2\end{array}$ \\
\hline $\operatorname{ROS}\left(\times 10^{6} \mathrm{cpm}\right)$ & $0.1(0.09,0.65)$ & $63(6.1,451)$ & $3.2(0.7,13)$ & .02 & .03 & .04 \\
\hline TAC (Trolox equivalent) & $985(825,1,755)$ & $563(409,814)$ & $1,003(901,1,251)$ & .02 & .85 & .01 \\
\hline ROS-TAC score & $53(51,63)$ & $33(29,39)$ & $50(45,55)$ & .005 & .06 & .01 \\
\hline Seminal leukocytes $\left(\times 10^{6} / \mathrm{mL}\right)$ & $0.1(0,0.2)$ & $1.8(0.6,4.4)$ & $0.0(0.0,0.4)$ & .006 & .2 & .01 \\
\hline
\end{tabular}

kines, granulosa cells, and leukocytes. Because it was not clear whether ROS are endogenous to this environment, Attaran et al. (106) examined the presence of ROS in the follicular fluid of women undergoing IVF and its role in pregnancy outcome. They also investigated the impact of follicular fluid ROS on oocyte maturation, fertilization, and pregnancy. Levels of ROS and TAC were measured in the follicular fluid of 53 women. Patient age, number of oocytes retrieved, percentage of oocytes fertilized, and levels of ROS and TAC were compared in women who did and did not become pregnant.

Women who became pregnant had significantly higher ROS levels. In addition, women with endometriosis or a partner with male-factor infertility who became pregnant had significantly higher ROS levels than those who did not (Table 5). On the basis of these findings, it may be speculated that follicular fluid ROS, at low concentrations, may be a potential marker for predicting success in IVF patients.
Oxidative stress was more evident in the follicular fluid of women who smoked. This may provide an explanation for impaired folliculogenesis in association with smoking (107). However, the developmental competence of oocytes retrieved during IVF is a multifactorial process that cannot be attributed to OS alone (108).

\section{Hydrosalpingeal Fluid Embryotoxicity and OS Parameters}

Because the exact mechanism by which hydrosalpingeal fluid (HSF) induces its embryotoxic effect is unknown, we hypothesized that an OS-mediated mechanism may be involved in this phenomenon. In a study to characterize OS parameters in HSF and examine their possible role in early embryo development, we aspirated HSF at laparoscopic salpingectomy in 11 infertile women (109). Reactive oxygen species, TAC, and LPO were assayed. Two-cell mouse embryos were incubated with $25 \%, 50 \%$ and $75 \%$ concentra-

\section{TABLE 5}

Unprocessed ROS and TAC levels in the follicular fluid of female patients with various diagnoses.

\begin{tabular}{|c|c|c|c|c|c|c|c|c|}
\hline \multirow[b]{2}{*}{ Diagnosis } & \multicolumn{2}{|c|}{ Pregnancy } & \multicolumn{3}{|c|}{$\operatorname{ROS}(\log +1)$} & \multicolumn{3}{|c|}{$\mathrm{TAC}$} \\
\hline & Yes & No & Pregnant & Nonpregnant & $P$ & Pregnant & Nonpregnant & $P$ \\
\hline Tubal disease $(\mathrm{n}=12)$ & 4 & 8 & $0.61 \pm 0.32$ & $0.70 \pm 0.18$ & .79 & $651.5 \pm 173.9$ & $737.3 \pm 10.0$ & .68 \\
\hline $\begin{array}{l}\text { Partner with male-factor } \\
\text { infertility }(\mathrm{n}=15)\end{array}$ & 6 & 9 & $1.31 \pm 0.19$ & $0.67 \pm 0.16$ & .01 & $884.6 \pm 100.4$ & $688.3 \pm 69.1$ & .15 \\
\hline Endometriosis $(\mathrm{n}=12)$ & 4 & 8 & $1.44 \pm 0.23$ & $0.60 \pm 0.17$ & .006 & $646.1 \pm 122.9$ & $811.1 \pm 86.9$ & .28 \\
\hline $\begin{array}{l}\text { Idiopathic infertility } \\
\qquad(\mathrm{n}=11)\end{array}$ & 3 & 8 & $0.58 \pm 0.27$ & $0.62 \pm 0.17$ & .89 & $850.2 \pm 142.0$ & $739.3 \pm 86.9$ & .52 \\
\hline Other $(\mathrm{n}=3)$ & 1 & 2 & 0.50 & $1.34 \pm 0.33$ & NA & 1239.2 & $573.3 \pm 173.9$ & NA \\
\hline
\end{tabular}

Values are mean \pm SE. $P<.05$ was considered significant by Student's $t$ test.

$\mathrm{NA}=$ not available; sample size did not provide adequate comparison.

Agarwal. ROS and human reproduction. Fertil Steril 2003. 
Comparison of ROS values between unprocessed $(\mathbf{A})$ and processed (B) peritoneal fluid from patients with endometriosis, patients with idiopathic infertility, and patients after tubal ligation. Each box plot covers the middle $50 \%$ of the data between the lower and upper quartiles. Central horizontal line represents the median, and the vertical line indicates the range of data.
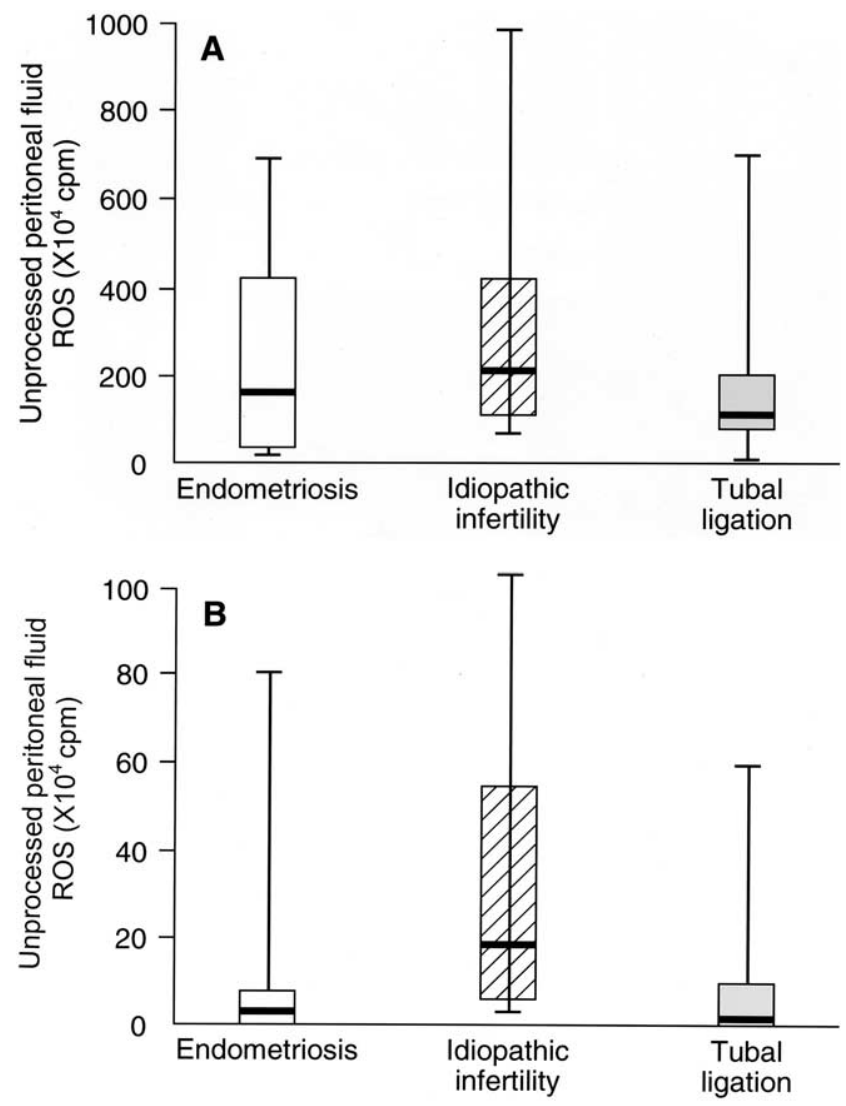

Agarwal. ROS and human reproduction. Fertil Steril 2003.

tions of HSF, and the blastocyst development rate was observed at each HSF concentration. Although ROS was detected in $45 \%$ of HSF samples and LPO was detected in all samples, only traces of TAC were detected in two samples. Despite the concentration-dependent embryotoxicity of the HSF, the blastocyst development rate was positively correlated with ROS levels but was not significantly correlated with LPO (Table 6).

In that study, we demonstrated for the first time the presence of ROS, LPO, and TAC in human HSF. There was a trend toward higher blastocyst development rate with low levels of ROS in the HSF compared with HSF devoid of ROS. We speculate that the low level was beneath the threshold for being deleterious to the embryos and may represent normal ROS generation by a functional endosalpinx, whereas HSF with nondetectable ROS levels is derived
Relationship of HSF concentration, ROS, and LPO levels with blastocyst development rate.

\begin{tabular}{lccc}
\hline Variable & $P$ value & $\begin{array}{c}\text { Odds } \\
\text { ratio }\end{array}$ & $\begin{array}{c}95 \% \text { Confidence } \\
\text { interval }\end{array}$ \\
\hline HSF concentration $(\%)$ & $<.0001$ & 0.28 & $0.17-0.46$ \\
ROS $\left(\times 10^{4} \mathrm{cpm}\right)$ & .02 & 1.80 & $1.09-2.98$ \\
LPO $(\mu \mathrm{mol}$ MDA/L) & .2 & - & - \\
\hline$P<.05$ was considered significant. & & \\
Agarwal. ROS and human reproduction. Fertil Steril 2003.
\end{tabular}

from hydrosalpinges with more extensive endosalpingeal damage. Low ROS levels may be a marker of normal tubal secretory function.

\section{Reactive Oxygen Species in the IVF Media}

Spermatozoa selected for ARTs most likely originate from an environment experiencing OS, and a high percentage of these sperm may have damaged DNA $(45,77)$. The question of OS-induced DNA damage is especially relevant during the ICSI procedure. Live spermatozoa have a plasma membrane that may release ROS before they reach the sperm nucleus. At the same time, during ICSI, the sperm plasma membrane has to be damaged before the injection to allow sperm-egg interaction (110). This may make the sperm nucleus more accessible for ROS that potentially can induce DNA breaks.

In addition, during sperm introduction, some medium is injected directly into the egg, increasing the risk of maternal DNA damage by ROS. Although the exact mechanism by which ROS induce DNA breaks is not known, it is well established that certain cations, such as iron or copper, may facilitate DNA damage, whereas other substances, such as catalase, may protect DNA from damage by acting as ROS scavengers (111). In vitro fertilization media are complex mixtures, and their modulation of ROS-induced DNA damage can be determined only experimentally (112). In vitro fertilization media and their components vary widely in their ability to modulate ROS-induced damage to DNA.

It has been reasoned previously that Ham's F-10 medium may facilitate DNA damage by ROS because it contains iron and copper (113). Indeed, the reaction mixture that contained iron in concentrations equal to those in Ham's F-10 medium caused complete plasmid relaxation (113). Nevertheless, there was not any DNA damage in the presence of Ham's F-10 medium as long as external iron was omitted from the reaction. Ham's F-10 medium is apparently safe from the point of DNA damage. However, unlike HTF and P-1 media, Ham's F-10 medium does not protect DNA from damage. Some media supplements, such as $1 \%$ Percoll, superoxide dismutase (1, 10, and $100 \mathrm{IU})$, and 10\% SSR2, do not protect DNA from damage. 
Relationship of day 1 ROS and percentage of embryos with high ( $>7$ cells) number of cells in ICSI cycles. Day 1 ROS levels were negatively correlated with percentage of embryos with high cell number at day $3(P=.01)$.

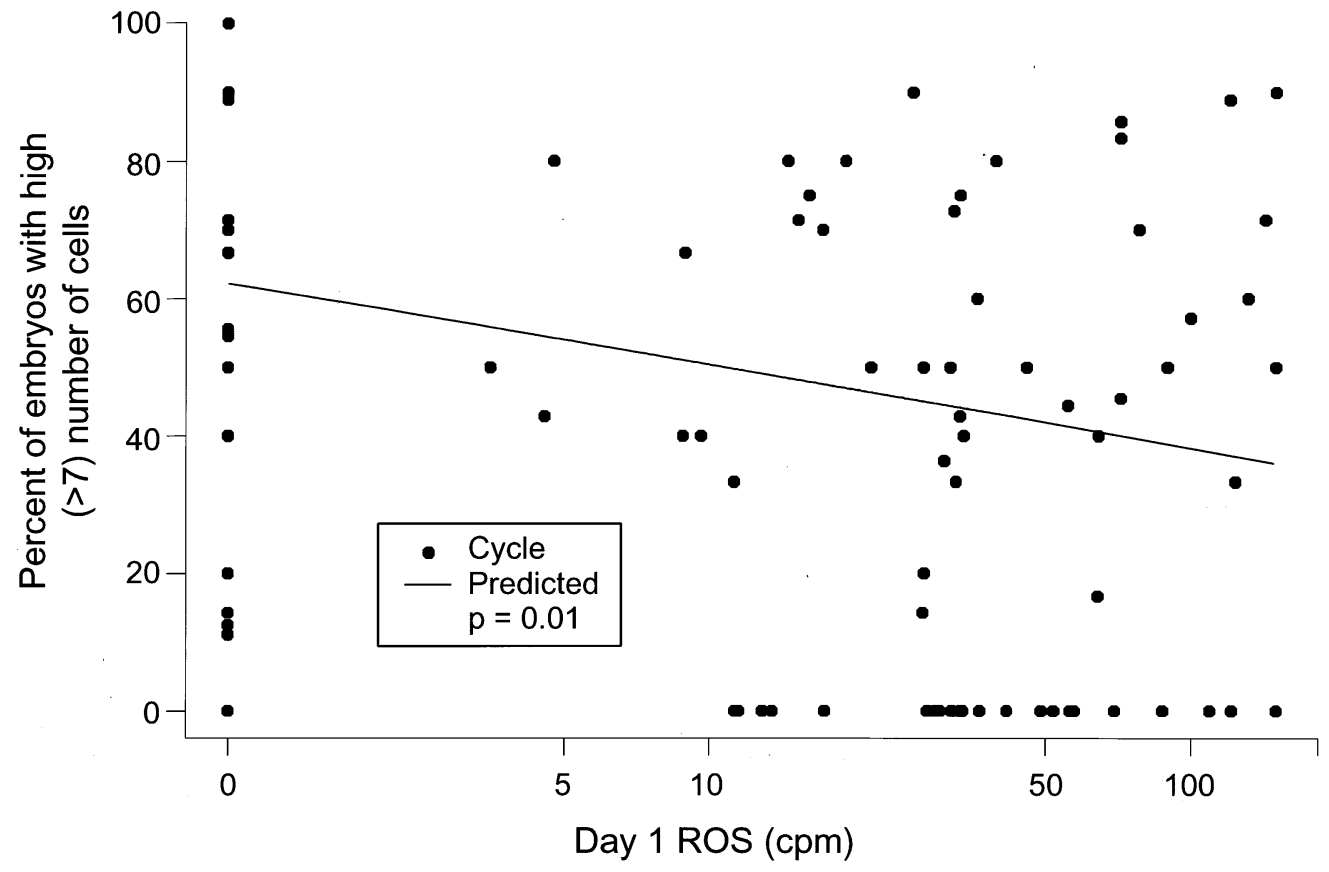

Agarwal. ROS and human reproduction. Fertil Steril 2003.

Other IVF media supplements, such as HSA $(10 \mathrm{mg} / \mathrm{mL})$, phenol red $(1,10$, and $100 \mu \mathrm{g} / \mathrm{mL})$, glucose $(2.78 \mathrm{mM}), 1 \%$ PVA, 5\% PVP, sucrose (100 mM), 60\% Percoll, HTF, P1 media, catalase (1 and $10 \mathrm{IU})$, and HEPES (21 mM) acted as ROS scavengers and protected the DNA from damage (112). Sperm manipulation media are usually supplemented with both HEPES and polyvinylpyrrolidone (PVP), which are potent DNA protectors. Therefore, it is likely that sperm DNA is well protected from damage by ROS during micromanipulation. The same applies to the oocyte DNA because HEPES and PVP are injected into the oocyte along with the spermatozoon (112). Recently, ROS levels were measured in day 1 culture media of ICSI cycles.

It was found that high levels of ROS in the culture system negatively affect the in vitro development of embryos as well as pregnancy rates in ICSI cycles (unpublished data). In conclusion, IVF media and their components vary widely in the way they affect DNA damage by ROS, and it may be worthwhile to test new media components for their ability to facilitate DNA damage before using them in a clinical setting.

\section{Reactive Oxygen Species in Human Embryos}

In human IVF, only few oocytes develop to be goodquality embryos, depending on the incubation conditions and the quality of the ovum and the spermatozoon, whereas the rest of them show abnormal morphology due to unequal cell division or fragmentation of the cell (114). Fragmented embryos have a limited developmental potential and rarely result in implantation $(115,116)$. Such abnormal embryo development has been reported to be due to inadequate culture environment. The in vitro culture environment differs from in vivo conditions in that the oxygen concentration is higher, and, in such a condition, mouse embryos show a higher ROS concentration in simple culture media (117, 118). Reactive oxygen species are thought to cause damage to the cell membrane (119) and to cause DNA fragmentation in somatic cells (120), and they may participate in the process of apoptosis (121). Apoptotic configurations in fragmented human embryos were observed at a stage before blastocyst formation, and these have been suggested as the process of programmed cell death (122).

\section{Relationship of Day 1 ROS in the Culture Media With Embryonic Development and ARTs Outcome}

Pregnancy rates in ARTs are suboptimal despite substantial technical improvements in the last decade. Better understanding of in vitro embryonic growth is very important. However, little is known about the biological, biochemical, and metabolic functions of preimplantation embryos. The embryonic secretory activities, paracrine functions, and met- 
Relationship of day 1 ROS and percentage of embryos with low $(<10 \%)$ fragmentation in ICSI cycles. Day 1 ROS levels were significantly related with increased embryonic fragmentation at day $3(P=.03)$.

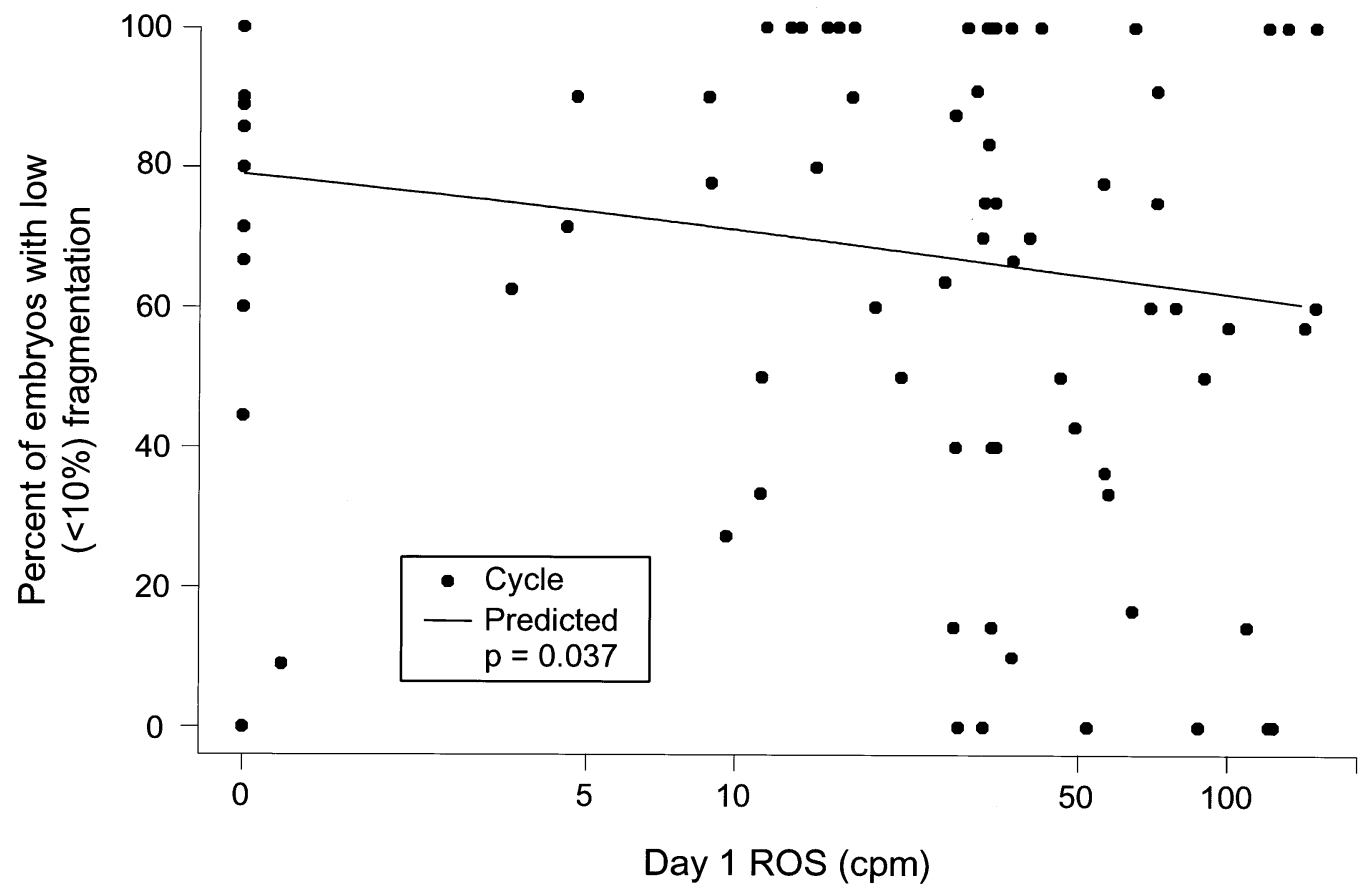

Agarwal. ROS and human reproduction. Fertil Steril 2003.

abolic byproducts have never been studied in a satisfactory manner. In a recent study, we examined the relationship of day 1 culture media ROS (D-1 ROS) levels and parameters of early human embryonic development. Patients undergoing IVF ( $\mathrm{n}=182 ; 93$ with ICSI in 108 cycles and 89 without ICSI in 108 cycles) were included.

Fertilization and early culture were performed in HTF with $5 \%$ serum substitute supplement. Day 1 ROS levels in the central well (sample) and the outer well (control) of each embryo culture dish were measured after overnight incubation by enhanced chemiluminescence assay using luminol as the probe. Fertilization rate and day 3 and day 5 embryo quality parameters were recorded for each cycle. Patients were comparable regarding age, parity, and demographic features. In the ICSI cycles, we found that D-1 ROS levels were negatively correlated with percentage of embryos with high cell number at day $3(P=.01$; Fig. 4$)$. Moreover, it was significantly related to increased embryonic fragmentation at day $3(P=.03$; Fig. 5) (123).

However, such a relationship could not be determined in the IVF cycles. This may be due to the heterogeneous cellularity in the IVF culture dish that contains spermatozoa, oocytes, and thousands of granulosa cells. From these findings, we can speculate that the ROS level in day 1 culture media is an important biochemical marker for early embry- onic growth. It has a strong relationship with early embryonic development, particularly the cleavage rate and increased embryo fragmentation. Whether this is a cause and/or effect needs further assessment.

The differential growth of ICSI embryos incubated under the same conditions may be due to differences in ROS levels surrounding them. This biological marker could help modulate the culture conditions for better embryonic outcome. Higher levels of ROS in day 1 culture media may indicate that the embryos will do poorly in culture, so early embryo transfer can be advised. These radicals may negatively affect the embryonic cell membrane. When ROS exceed a certain level, the PUFA in the blastomere cell membrane oxidizes, resulting in a decrease in the membrane fluidity and inducing fragmentation. Moreover, disturbed membrane function may lead to delayed compaction, cavitation, and blastulation.

\section{CONCLUSION}

Oxidative stress can arise as a consequence of excessive production of ROS and/or impaired antioxidant defense mechanisms. The extensive literature review that we have conducted indicates that OS precipitate a range of pathologies currently thought to afflict the reproductive function. In the context of male reproduction, clear evidence suggests 
that human sperm can produce ROS. It follows that some spermatozoa will incur oxidative damage that may account for the defective sperm function observed in a high proportion of infertility patients. Unfortunately, spermatozoa are unable to repair the damage induced by excessive ROS because they lack the cytoplasmic enzyme systems required to accomplish this repair. This is one of the features that make spermatozoa unique in their susceptibility to oxidative insult.

Oxidative stress attacks the fluidity of the sperm plasma membrane and the integrity of DNA in the sperm nucleus. Reactive oxygen species-induced DNA damage may accelerate the process of germ cell apoptosis, leading to the decline in sperm counts associated with male infertility and the apparent deterioration of semen quality observed over the past 4 to 5 decades. Given the reproductive importance of the peritoneal fluid, it was the focus of research studies conducted recently in our center with the aim of defining the relationship between its ROS levels and different female infertility problems. Reactive oxygen species were present in the peritoneal fluid of patients with endometriosis and idiopathic infertility and in those who underwent tubal ligation. However, levels of ROS in patients with endometriosis and the control group were not significantly different, but these did differ significantly between patients with idiopathic infertility and controls. Therefore, ROS may play a role in patients with idiopathic infertility.

The impact of follicular fluid ROS on oocyte maturation, fertilization, and pregnancy was also investigated in our center. Our results indicate that follicular fluid ROS, at low concentrations, may be a potential marker for predicting success in IVF patients. In addition, our studies have demonstrated for the first time the presence of ROS, LPO, and TAC in human HSF. There was a trend toward higher blastocyst development rate with low levels of ROS in the HSF compared with HSF devoid of ROS. We speculated that the low levels were beneath the threshold for being deleterious to the embryos and may represent normal ROS generation by a functional endosalpinx, whereas HSF with nondetectable ROS levels is derived from hydrosalpinges with more extensive endosalpingeal damage. Thus, the low ROS level may be a marker of normal tubal secretory function.

Furthermore, we have shown that the ROS level in day 1 culture media is an important biochemical marker for early embryonic growth. It has a strong relationship with the early embryonic development, particularly the cleavage rate and increased embryo fragmentation. Whether this is a cause and/or effect needs further assessment. In summary, small physiological amounts of ROS play an important role in normal reproductive function, whereas high levels mediate a wide range of pathological condition that affect human fertility. Treatment strategies must be directed toward lowering of ROS levels to keep only a small amount necessary to maintain normal cell function.

Acknowledgments: The authors thank the following members of our research team for contributing to studies described in this review: Rakesh Sharma, Ph.D., Mohammad Shekarriz, M.D., Rajinder Singh Sidhu, M.D., Yongjin Wang, M.D., Jorge Hallak, M.D., Benjamin Hendin, M.D., Peter Kolettis, M.D., James Daitch, M.D., Fabio Pasqualotto, M.D., Hiroshi Kobayashi, M.D., Enrique Gil Guzman, M.D., Xia Wang, M.D., Mohamed Moustafa, M.D., David R. Nelson, M.S., Julie Thornton, M.S., Anthony J. Thomas Jr., M.D., and Tommaso Falcone, M.D. We also thank members of the Clinical Andrology Laboratory, Karen Seifarth, M.T. (A.S.C.P.), Cheryl Wellstead, M.T. (A.S.C.P.), and Lora Cordek, M.T. (A.S.C.P.), who provided technical support for these studies. We also wish to thank Robin Verdi for providing secretarial support.

\section{References}

1. de Lamirande E, Gagnon C. Impact of reactive oxygen species on spermatozoa: a balancing act between beneficial and detrimental effects. Hum Reprod 1995;10:15-21.

2. Sikka SC. Relative impact of oxidative stress on male reproductive function. Curr Med Chem 2001;8:851-62.

3. Sharma RK, Agarwal A. Role of reactive oxygen species in male infertility [review]. Urology 1996;48:835-50.

4. Padron OF, Brackett NL, Sharma RK, Kohn S, Lynne CM, Thomas AJ Jr, et al. Seminal reactive oxygen species, sperm motility and morphology in men with spinal cord injury. Fertil Steril 1997;67: 1115-20.

5. Sikka SC. Oxidative stress and role of antioxidants in normal and abnormal sperm function. Front Biosci 1996;1:78-86.

6. Alvarez JG, Storey BT. Differential incorporation of fatty acids into and peroxidative loss of fatty acids from phospholipids of human spermatozoa. Mol Reprod Dev 1995;42:334-46.

7. Iwasaki A, Gagnon C. Formation of reactive oxygen species in spermatozoa of infertile patients. Fertil Steril 1992;57:409-16.

8. Aitken RJ. A free radical theory of male infertility. Reprod Fertil Dev 1994;6:19-24.

9. Aitken RJ. The Amoroso lecture. The human spermatozoon-a cell in crisis? J Reprod Fertil 1999;115:1-7.

10. Gagnon C, Iwasaki A, de Lamirande E, Kovalski N. Reactive oxygen species and human spermatozoa. Ann NY Acad Sci 1991;637:436-44.

11. de Lamirande E, Gagnon C. Reactive oxygen species (ROS) and reproduction. Adv Exp Med Biol 1994;366:185-97.

12. Aitken RJ. Molecular mechanisms regulating human sperm function. Mol Hum Reprod 1997;3:169-73.

13. Aitken RJ, Clarkson JS, Fishel S. Generation of reactive oxygen species, lipid peroxidation, and human sperm function. Biol Reprod 1989;40:183-97.

14. de Lamirande E, Gagnon C. Human sperm hyperactivation and capacitation as parts of an oxidative process. Free Radic Biol Med 1993;14:255-65.

15. Zini A, de Lamirande E, Gagnon C. Low levels of nitric oxide promote human sperm capacitation in vitro. J Androl 1996;16:42431 .

16. Alvarez JG, Storey BT. Taurine, hypotaurine, epinephrine and albumin inhibit lipid peroxidation in rabbit spermatozoa and protect against loss of motility. Biol Reprod 1983;29:548-55.

17. Sies H. Strategies of antioxidant defence. Eur J Biochem 1993;215: 213-9.

18. Armstrong JS, Rajasekaran M, Hellstrom WJ, Sikka SC. Antioxidant potential of human serum albumin: role in the recovery of high quality human spermatozoa for assisted reproductive technology. J Androl 1998;19:412-9.

19. Donnelly ET, McClure N, Lewis S. Antioxidant supplementation in vitro does not improve human sperm motility. Fertil Steril 1999;72: 484-95.

20. Wefers $\mathrm{H}$, Sies $\mathrm{H}$. The protection by ascorbate and glutathione against microsomal lipid peroxidation is dependent on vitamin E. Eur J Biochem 1988;174:353-7. 
21. Buettner GR. The pecking order of free radicals and antioxidants, lipid peroxidation, alpha-tocopherol and ascorbate. Arch Biochem Biophys 1993;300:535-43.

22. Sies H, Stahl W, Sundquist RA. Antioxidant function of vitamins. Vitamins E and C, beta-carotenoids, and other carotenoids. Ann NY Acad Sci 1992;669:7-20.

23. Lewis SEM, Boyle PM, McKinney KA, Young IS, Thompson W Total antioxidant capacity of seminal plasma is different in fertile and infertile men. Fertil Steril 1995;64:868-70.

24. Zini A, de Lamirande E, Gagnon C. Reactive oxygen species in the semen of infertile patients: levels of superoxide dismutase- and catalase-like activities in seminal plasma. Int J Androl 1993;16:183-8.

25. Aitken RJ. Free radicals, lipid peroxidation, sperm function. Reprod Fertil Dev 1995;7:659-68.

26. Fisher HM, Aitken RJ. Comparative analysis of the ability of precursor germ cells and epididymal spermatozoa to generate reactive oxygen metabolites. J Exp Zool 1997;277:390-400.

27. Hendin B, Kolettis P, Sharma RK, Thomas AJ Jr, Agarwal A. Varicocele is associated with elevated spermatozoal reactive oxygen species production and diminished seminal plasma antioxidant capacity. J Urol 1999;161:1831-4.

28. Gil-Guzman E, Ollero M, Lopez MC, Sharma RK, Alvarez JG, Thomas AJ Jr, et al. Differential production of reactive oxygen species by subsets of human spermatozoa at different stages of maturation. Hum Reprod 2001;16:1922-30.

29. Aitken RJ, Buckingham DW, West KM. Reactive oxygen species and human spermatozoa: analysis of the cellular mechanisms involved in luminol- and lucigenin-dependent chemiluminescence. J Cell Physiol 1992;151:466-77.

30. Gavella M, Lipovac V. NADH-dependent oxido-reductase (diaphorase) activity and isozyme pattern of sperm in infertile men. Arch Androl 1992;28:135-41.

31. Plante $\mathrm{M}$, de Lamirande $\mathrm{E}$, Gagnon C. Reactive oxygen species released by activated neutrophils, but not by deficient spermatozoa, are sufficient to affect normal sperm motility. Fertil Steril 1994;62: 387-93.

32. Gomez E, Irvine DS, Aitken RJ. Evaluation of a spectrophotometric assay for the measurement of malondialdehyde and 4-hydroxyalkenals in human spermatozoa: relationships with semen quality and sperm function. Int J Androl 1998;21:81-94.

33. Aitken RJ, West KM. Analysis of the relationship between reactive oxygen species production and leukocyte infiltration in fractions of human semen separated on Percoll gradients. Int J Androl 1990;3: 433-51.

34. Huszar G, Sbracia M, Vigue L, Miller DJ, Shur BD. Sperm plasma membrane remodeling during spermiogenic maturation in men: relationship among plasma membrane beta 1,4-galactosyltransferase, cytoplasmic creatine phosphokinase and creatine phosphokinase isoform ratios. Biol Reprod 1997;56:1020-4.

35. Huszar G, Vigue L. Incomplete development of human spermatozoa is associated with increased creatine phosphokinase concentration and abnormal head morphology. Mol Reprod Dev 1993;34:292-8.

36. Sidhu RS, Sharma RK, Thomas AJ Jr, Agarwal A. Relationship between creatine kinase activity and semen characteristics in subfertile men. Int J Fertil Wom Med 1998;43:192-7.

37. Hallak J, Sharma RK, Pasqualotto FF, Ranganathan P, Thomas AJ Jr, Agarwal A. Creatine kinase as an indicator of sperm quality and maturity in men with oligospermia. Urology 2001;58:446-51.

38. Huszar G, Vigue L. Correlation between the rate of lipid peroxidation and cellular maturity as measured by creatine kinase activity in human spermatozoa. J Androl 1994;15:71-7.

39. Ollero M, Gil-Guzman E, Lopez MC, Sharma RK, Agarwal A, Larson $\mathrm{KL}$, et al. Characterization of subsets of human spermatozoa at different stages of maturation: implications in the diagnosis and treatment of male infertility. Hum Reprod 2001;16:1912-21.

40. World Health Organization. Laboratory manual for the examination of human semen and sperm-cervical mucus interaction. 4th ed. New York: Cambridge University Press, 1999

41. Kruger TF, Acosta AA, Simmons KF, Swanson RJ, Matta JF, Veeck LL, et al. New method of evaluating sperm morphology with predictive value for human in vitro fertilization. Urology 1987;30:248-51

42. Agarwal A, Ikemoto I, Loughlin KR. Levels of reactive oxygen species before and after sperm preparation: comparison of swim-up and L4 filtration methods. Arch Androl 1994;32:169-74

43. Agarwal A, Ikemoto I, Loughlin KR. Effect of sperm washing on reactive oxygen species level in semen. Arch Androl 1994;33:157-62.

44. Shekarriz M, Thomas AJ Jr, Agarwal A. A method of human semen centrifugation to minimize the iatrogenic sperm injuries caused by reactive oxygen species. Eur Urol 1995;28:31-5

45. Lopes S, Jurisicova A, Sun J, Casper RF. Reactive oxygen species: a potential cause for DNA fragmentation in human spermatozoa. Hum Reprod 1998;13:896-900.
46. Zini A, Finelli A, Phang D, Jarvi K. Influence of semen processing on human sperm DNA integrity. Urology 2000;56:1081-4.

47. Tomlinson MJ, White A, Barratt CL, Bolton AE, Cooke ID. The removal of morphologically abnormal sperm forms by phagocytes: a positive role for seminal leukocytes. Hum Reprod 1992;7:517-22.

48. Thomas J, Fishel SB, Hall JA, Green S, Newton TA, Thornton SJ Increased polymorphonuclear granulocytes in seminal plasma in relation to sperm morphology. Hum Reprod 1997;12:2418-21.

49. Wolff $\mathrm{H}$. The biologic significance of white blood cells in semen Fertil Steril 1995;63:1143-7.

50. Tomlinson MJ, Barrat GLR, Cooke ID. Prospective study of leukocytes and leukocyte subpopulations in semen suggests that they are not a cause of male infertility. Fertil Steril 1993;60:1069-75.

51. Aitken RJ, Krausz C, Buckingham D. Relationship between biochemical markers for residual sperm cytoplasm, reactive oxygen species generation and the presence of leukocytes and precursor germ cells in human sperm suspension. Mol Reprod Dev 1994;39:268-79.

52. Rajasekaran M, Hellstrom WJ, Naz RK, Sikka SC. Oxidative stress and interleukins in seminal plasma during leukocytospermia. Fertil Steril 1995;64:166-71.

53. Shekarriz M, Sharma RK, Thomas AJ Jr, Agarwal A. Positive myeloperoxidase staining (Endtz Test) as an indicator of excessive reactive oxygen species formation in semen. J Assist Reprod Genet 1995 $12: 70-4$.

54. Pasqualotto FF, Sharma RK, Agarwal A, Nelson DR, Thomas AJ Jr, Potts JM. Seminal oxidative stress in chronic prostatitis patients. Urology 2000;55:881-5.

55. Saran M, Beck-Speier I, Fellerhoff B, Bauer G. Phagocytic killing of microorganisms by radical processes: consequences of the reaction of hydroxyl radicals with chloride yielding chlorine atoms. Free Radic Biol Med 1999;26:482-90.

56. Ochsendorf FR. Infections in the male genital tract and reactive oxygen species. Hum Reprod 1999;5:399-420.

57. Sharma R, Pasqualotto FF, Nelson DR, Thomas AJ Jr, Agarwal A Relationship between seminal white blood cell counts and oxidative stress in men treated at an infertility clinic. J Androl 2001;22:575-83.

58. Kovalski NN, de Lamirande E, Gagnon C. Reactive oxygen species generated by human neutrophils inhibit sperm motility: protective effects of seminal plasma and scavengers. Fertil Steril 1992;58:809_ 16.

59. Saleh RA, Agarwal A, Kandirali E, Sharma RK, Thomas AJ Jr, Nada EA, et al. Leukocytospermia is associated with increased reactive oxygen species production by human spermatozoa. Fertil Steril. 2002; 78:1215-24.

60. Spitteler G. Review: on the chemistry of oxidative stress. J Lipid Mediat 1993;7:77-82.

61. Jannsen YM, Van-Houton B, Borm PJ, Mossuran BT. Cell and tissue responses to oxidative damage. Lab Invest 1993;69:261-5.

62. de Lamirande E, Jiang H, Zini A, Kodoma H, Gagnon C. Reactive oxygen species (ROS) and sperm physiology. Rev Reprod 1997;2:4854

63. Sikka SC, Rajasekaran M, Hellstrom WJG. Role of oxidative stress and antioxidants in male infertility. J Androl 1995;16:464-8

64. Halliwell B. How to characterize a biological antioxidant. Free Radic Res Commun 1990;9:1-32

65. Aitken RJ, Fisher H. Reactive oxygen species generation and human spermatozoa: the balance of benefit and risk. Bioassays 1994;16:25967.

66. Lenzi A, Cualosso F, Gandini L, Lombardo F, Dondero F. Placebocontrolled, double-blind, cross-over trial of glutathione therapy, in male infertility. Hum Reprod 1993;9:2044-50.

67. Agarwal A, Ikemoto I, Loughlin KR. Relationship of sperm parameters to levels of reactive oxygen species in semen specimens. J Urol 1994; $152: 107-10$.

68. Armstrong JS, Rajasekaran M, Chamulitrat W, Gatti P, Hellstrom WJ, Sikka SC. Characterization of reactive oxygen species induced effects on human spermatozoa movement and energy metabolism. Free Radic Biol Med 1999;26:869-80.

69. de Lamirande E, Gagnon C. Reactive oxygen species and human spermatozoa. II. Depletion of adenosine triphosphate (ATP) plays an important role in the inhibition of sperm motility. J Androl 1992;13: 379-86.

70. Aitken RJ, Fisher H, Fulton N, Gomez E, Knox W, Lewis B, et al. Reactive oxygen species generation by human spermatozoa is induced by exogenous NADPH and inhibited by flavoprotein inhibitors diphenylene iodonium and quinacrine. Mol Reprod Dev 1997;47:468-82.

71. Griveau JF, Dumont E, Renard B, Callegari JP, Lannou DL. Reactive oxygen species, lipid peroxidation and enzymatic defense systems in human spermatozoa. J Reprod Fertil 1995;103:17-26.

72. Twigg J, Irvine DS, Aitken RJ. Oxidative damage to DNA in human spermatozoa does not preclude pronucleus formation at intracytoplasmic sperm injection. Hum Reprod 1998;13:1864-71. 
73. Duru NK, Morshedi M, Oehninger S. Effects of hydrogen peroxide on DNA and plasma membrane integrity of human spermatozoa. Fertil Steril 2000;74:1200-7.

74. Aitken RJ, Krausz C. Oxidative stress, DNA damage and the Y chromosome. Reproduction 2001;122:497-506.

75. Fraga GG, Motchnik PA, Shigenaga MK, Helbrock JH, Jacob RA, Ames B. Ascorbic acid protects against endogenous oxidative DNA damage in human sperm. Proc Natl Acad Sci USA 1991;88:11003-6.

76. Fraga GG, Motchnik P, Wyrobek AJ, Rempel DM, Ames B. Smoking and low antioxidant levels increase oxidative damage to sperm DNA. Mutat Res 1996;351:199-203.

77. Kodama H, Yamaguchi R, Fukuda J, Kasai H, Tanaka T. Increased oxidative deoxyribonucleic acid damage in the spermatozoa of infertile male patients. Fertil Steril 1997;65:519-24.

78. Sun JG, Jurisicova A, Casper RF. Detection of deoxyribonucleic acid fragmentation in human sperm: correlation with fertilization in vitro. Biol Reprod 1997;56:602-7

79. Twigg J, Irvine DS, Houston P, Fulton N, Michael L, Aitken RJ. Iatrogenic DNA damage induced in human spermatozoa during sperm preparation: protective significance of seminal plasma. Mol Hum Reprod 1998;4:439-45.

80. Vaux DL, Flavell RA. Apoptosis genes and autoimmunity. Curr Opin Immunol 2000;12:719-24.

81. Vaux DL, Korsmeyer SJ. Cell death in development. Cell 1999;96: 245-54.

82. Sakkas D, Mariethoz E, Manicardi G, Bizzaro D, Bianchi P, Bianchi U. Origin of DNA damage in ejaculated human spermatozoa. Rev Reprod 1999;4:31-7.

83. Sinha Hikim AP, Swerdloff RS. Hormonal and genetic control of germ cell apoptosis in the testis. Rev Reprod 1999;4:38-47.

84. Blanco-Rodriguez J. A matter of death and life: the significance of germ cell death during spermatogenesis. Int J Androl 1998;21:23648.

85. Hasegawa M, Zhang Y, Niibe H, Terry NH, Meistrich ML. Resistance of differentiating spermatogonia to radiation-induced apoptosis and loss in p53-deficient mice. Radiat Res 1998;149:263-70.

86. Kemp CJ, Sun S, Gurley KE. p53 induction and apoptosis in response to radio- and chemotherapy in vivo is tumor-type-dependent. Cancer Res 2001;61:327-32.

87. Lee J, Richburg JH, Younkin SC, Boekelheide K. The Fas system is a key regulator of germ cell apoptosis in the testis. Endocrinology 1997;138:2081-8.

88. Sinha Hikim AP, Wang C, Lue Y, Johnson L, Wang XH, Swerdloff RS. Spontaneous germ cell apoptosis in humans: evidence for ethnic differences in the susceptibility of germ cells to programmed cell death. J Clin Endocrinol Metab 1998;83:152-6.

89. Jurisicova A, Lopes S, Meriano J, Oppedisano L, Casper RF, Varmuza $\mathrm{S}$. DNA damage in round spermatids of mice with a targeted disruption of the Pplcgamma gene and in testicular biopsies of patients with non-obstructive azoospermia. Mol Hum Reprod 1999;5:323-30.

90. Gandini L, Lombardo F, Paoli D, Caponecchia L, Familiari G, Verlengia C, et al. Study of apoptotic DNA fragmentation in human spermatozoa. Hum Reprod 2000;15:830-9.

91. Sentman CL, Shutter JR, Hockenbery D, Kanagawa O, Korsmeyer SJ. Bcl-2 inhibits multiple forms of apoptosis but not negative selection in thymocytes. Cell 1991;67:879-88.

92. Kane DJ, Sarafian TA, Anton R, Hahn H, Gralla EB, Valentine JS, et al. Bcl-2 inhibition of neural death: decreased generation of reactive oxygen species. Science 1993;262:1274-7.

93. Krammer PH, Behrmann I, Daniel P, Dhein J, Debatin KM. Regulation of apoptosis in the immune system. Curr Opin Immunol 1994;6: 279-89.

94. Suda T, Takahashi T, Golstein P, Nagata S. Molecular cloning and expression of Fas ligand, a novel member of the tumor necrosis factor family. Cell 1993;75:1169-78.

95. Sharma RK, Pasqualotto FF, Nelson DR, Thomas AJ Jr, Agarwal A The reactive oxygen species-total antioxidant capacity score is a new measure of oxidative stress to predict male infertility. Hum Reprod 1999; $14: 2801-7$

96. Alvarez JG, Touchstone JC, Blasco L, Storey BT. Spontaneous lipid peroxidation and production of hydrogen peroxide and superoxide in human spermatozoa: superoxide dismutase as a major enzyme protectant against oxygen toxicity. J Androl 1987;8:336-48

97. Kobayashi H, Gil-Guzman E, Mahran AM, Sharma RK, Nelson DR, Thomas AJ Jr, et al. Quality control of reactive oxygen species measurement by luminol-dependent chemiluminescence assay. J Androl 2000;22:568-74.

98. Kolettis P, Sharma RK, Pasqualotto F, Nelson D, Thomas AJ Jr, Agarwal A. The effects of seminal oxidative stress on fertility after vasectomy reversal. Fertil Steril 1999;71:249-55
99. Pasqualotto FF, Sharma RK, Nelson DR, Thomas AJ Jr, Agarwal A Relationship between oxidative stress, semen characteristics, and clinical diagnosis in men undergoing fertility investigation. Fertil Steril 2000;73:459-64

100. Pasqualotto FF, Sharma RK, Kobayashi H, Nelson DR, Thomas AJ Jr, Agarwal A. Oxidative stress in normospermic men undergoing infertility evaluation. J Androl 2001;73:459-64.

101. Daitch JA, Bedaiway MA, Pasqualotto FF, Hendin B, Hallak J, Falcone T, et al. Varicocelectomy improves intrauterine insemination success rates among men with varicocele. J Urol 2001;165:1510-3.

102. Agarwal A, Ikemoto I, Loughlin KR. Prevention of testicular damage by free-radical scavengers. Urology 1997;50:759-63.

103. Saleh R, Agarwal A, Sharma RK, Nelson DR, Thomas AJ Jr. Effect of cigarette smoking on levels of seminal oxidative stress in infertile men: a prospective study. Fertil Steril 2002;78:491-9.

104. Wang Y, Sharma RK, Falcone T, Goldberg J, Agarwal A. Importance of reactive oxygen species in the peritoneal fluid of women with endometriosis or idiopathic infertility. Fertil Steril 1997;68:826-30.

105. Bedaiwy MA, Falcone T, Sharma RK, Goldberg JM, Attaran M, Nelson DR, et al. Prediction of endometriosis with serum and peritoneal fluid markers: a prospective controlled trial. Hum Reprod 2002; $17: 426-31$.

106. Attaran M, Pasqualotto E, Falcone T, Goldberg JM, Miller KF, Agarwal A, et al. The effect of follicular fluid reactive oxygen species on the outcome of in vitro fertilization. Int J Fertil Wom Med 2000;45: $314-20$.

107. Paszkowski T, Clarke RN, Hornstein MD. Smoking induces oxidative stress inside the Graafian follicle. Hum Reprod 2002;17:921-5.

108. Jozwik M, Wolczynski S, Szamatowicz M. Oxidative stress markers in preovulatory follicular fluid in humans. Mol Hum Reprod 1999;5: 409-13.

109. Bedaiwy MA, Goldberg JM, Falcone T, Singh M, Nelson D, Azab H, et al. Relationship between oxidative stress and embryotoxicity of hydrosalpingeal fluid. Hum Reprod 2002;17:601-4.

110. Dozortsev D, Rybouchkin A, De Sutter P, Dhont M. Sperm plasma membrane damage prior to intracytoplasmic sperm injection: a necessary condition for sperm nucleus decondensation. Hum Reprod 1995; 10:2960-4

111. Toyokuni S, Sagripanti JL. Iron-mediated DNA damage: sensitive detection of DNA strand breakage catalyzed by iron. J Inorg Biochem 1992;47:241-8.

112. Ermilov A, Diamond MP, Sacco AG, Dozortsev DD. Culture media and their components differ in their ability to scavenge reactive oxygen species in the plasmid relaxation assay. Fertil Steril 1999;72: $154-7$.

113. Cummins JM, Jequier AM, Kan R. Molecular biology of human male infertility: links with aging, mitochondrial genetics, and oxidative stress? Mol Reprod Dev 1994;37:345-62.

114. Goyanes VJ, Ron-Corzo A, Costas E, Maneiro E. Morphometric categorization of the human oocyte and early conceptus. Hum Reprod 1990;5:613-8.

115. Plachot M, Mandelbaum J. Oocyte maturation, fertilization and embryonic growth in vitro. Br Med Bull 1990;46:675-94.

116. Erenus M, Zouves C, Rajamahendran P, Leung S, Fluker M, Gomel V. The effect of embryo quality on subsequent pregnancy rates after in vitro fertilization. Fertil Steril 1991;56:707-10.

117. Nasr-Esfahani MH, Aitken JR, Johnson MH. Hydrogen peroxide levels in mouse oocytes and early cleavage stage embryos developed in vitro or in vivo. Development 1990;109:501-7.

118. Goto Y, Noda Y, Mori T, Nakano M. Increased generation of reactive oxygen species in embryos cultured in vitro. Free Radic Biol Med 1993; 15:69-75.

119. Halliwell B, Chirico S. Lipid peroxidation: its mechanism, measurement, and significance. Am J Clin Nutr 1993;57:715S-24S.

120. Halliwell B, Aruoma OI. DNA damage by oxygen-derived species. Its mechanism and measurement in mammalian systems. FEBS Lett 1991;281:9-19.

121. Hockenbery DM, Oltvai ZN, Yin XM, Milliman CL, Korsmeyer SJ. Bcl-2 functions in an antioxidant pathway to prevent apoptosis. Cell 1993; 75:241-51.

122. Jurisicova A, Varmuza S, Casper RF. Programmed cell death and human embryo fragmentation. Mol Hum Reprod 1996;2:93-8.

123. Bedaiwy MA, Miller K, Falcone T, Nelson D, AbdelAleem A, Mohamed $\mathrm{M}$, et al. Differential growth of human embryos in vitro: role of reactive oxygen species. In: 18th Annual Meeting of the European Society of Human Reproduction and Embryology, 30 Jun-3 Jul, 2002, Vienna, Austria. Hum Reprod 2002;17:38. 